\title{
3 Research Square \\ Google-Reflected Information on Drugs Used for Anesthesia: Time Course of Growth in Number of Web Pages
}

\author{
Kamen V. Vlassakov \\ Brigham and Women's Hospital \\ Igor Kissin ( $\sim$ ikissin@bwh.harvard.edu ) \\ Brigham and Women's Hospital
}

\section{Research Article}

Keywords: Bibliometrics, General anesthetics, Google Web pages, Local anesthetics, Opioids, Scientometrics, World Wide Web.

Posted Date: May 28th, 2021

DOl: https://doi.org/10.21203/rs.3.rs-537199/v1

License: (c) (1) This work is licensed under a Creative Commons Attribution 4.0 International License.

Read Full License

Version of Record: A version of this preprint was published at Medical Research Archives on January 1st, 2022. See the published version at https://doi.org/10.18103/mra.v10i2.2688. 


\section{Abstract}

Purpose: The aim of this study was to determine the time course of growth in general Google-reflected information on drugs used for anesthesia. As a contrast to the changes in general Google-reflected information we used the changes in academic PubMed-reflected information.

Methods: General Google-reflected information on anesthetics was assessed by counting the number of Google Web pages. Academic information was assessed by counting the number of articles in medicobiological journals covered by the PubMed database (The National Library of Medicine). The ratio of Google Web pages to PubMed articles (G/P Ratio) was used to indicate prevalence of Google-related information. Twenty-five agents used for anesthesia were selected from three pharmacological groups general anesthetics, local anesthetics, and opioids -- based on the frequency of their association with anesthesia in academic medical journals. The time course of growth in general Google-reflected information was determined for seven 5-year periods, from 1983 to 2017.

Results: With the growing role of the Web, the number of Google Web pages on drugs used for anesthesia increased rapidly. As a result, the relationship between general Google-reflected and academic PubMedreflected information on anesthetics profoundly changed. Before the 1993-1997 period, the number of Google Web pages on anesthetics was only a fraction of the number of PubMed articles. By the 20132017period, the relationship was completely reversed: for any anesthetic, the number of Google Web pages was at least three times greater than the number of PubMed articles. However, the relationship of general Web-related information and academic information with different anesthetics was very variable. In 2013-2017, the G/P Ratio, indicating the magnitude of general information dominance, for the 25 agents varied from 3.0 (remifentanil) to 23.2 (oxycodone). The dominance of Google information was especially profound with drugs that have a wider spectrum of possible use beyond the field of anesthesia, such as oxycodone or diazepam.

Conclusion: General Google-reflected information is rapidly growing and, as a result, its dominance over academic PubMed-reflected information is constantly increasing.

\section{Introduction}

In previous studies, we examined how interest in various general and local anesthetics among the authors of academic publications changed over the past 50 years. ${ }^{1-3}$ It was found that over this time there was constant growth in the number of academic articles on these topics; in addition, there was a slowly developing concentration of publication-based academic interest on a very limited number of anesthetics. ${ }^{1-3}$ The development of the World Wide Web (the Web) massively increased both the amount and the access to general information on a multitude of subjects, including various drugs used during anesthesia. In addition to academic (scholarly) Web-pages that follow traditional bibliometrics, many other types of Web-based resources have been developed in the public domain, reflecting many aspects 
of human activity: commercial, educational, and social. ${ }^{4}$ The availability of Web-based information contributes to an increased general interest in any topic, including drugs used for anesthesia.

Before the Web, in-depth articles on drugs for anesthesia had a very limited reach beyond medical journals, due to factors such as access, language, style, peer-review process. However, the presence of various types of information on the Web, including the contents of academic journals, has grown enormously. In addition, the Web's "walls" separating academic and non-academic information have become more permeable for all types of users. Less than 20 years ago the number of Google Web pages on anesthetics was only a fraction of the number of articles on anesthetics in academic journals (PubMed database). Since then the growth of Google-reflected information has been dramatic and, as a result, the entire landscape of drug-related information has changed.

The aim of this study was to determine the time course of growth in general Google-reflected information on drugs used for anesthesia. As a contrast to the changes in general Google-reflected information we used the changes in academic PubMed-reflected information.

\section{Methods}

The general Web-based information on an anesthetic was assessed by counting the number of Google Web pages found via its Advanced Search service, which allows the use of specific customized search options. Academic information on an anesthetic drug was assessed by counting the number of articles in medico-biological journals covered by the PubMed database (the National Library of Medicine, website http://www.ncbhi.nlm.nih.gov/pubmed) using its Custom Search service. The changes in PubMedreflected information over time were used as the contrast to better assess the changes in Google-reflected information. To make such Google-PubMed juxtaposition more equitable, the following requirements for drug searches were applied: 1) Only those Google Web pages and PubMed articles were counted that had a specific term (the name of a drug) in the title of the Web page or the title of the article ("term-in-title"). 2) Only commonly accepted nonproprietary names of the drugs were used. 3) Only results in English were counted. As a result, in the advanced Google search setting the following filters were used: Language English, Exact word - the nonproprietary name of a drug, Location of term appendage - the title of the page, Specified time - custom range.

The ratio of Google Web pages to PubMed articles (G/P Ratio) was used to indicate Google-related dominance. The time course of growth in general Google-reflected and academic PubMed-reflected information was determined for seven 5-year periods: 1983-87, 1988-92, 1993-97, 1998-09, 2003-07, 2008-12, and 2013-17.

Three categories of agents were selected for analysis: general anesthetics (including agents used for general anesthesia that belong to pharmacological groups also used for other indications as well, such as dexmedetomidine), local anesthetics, and opioids. Two criteria were used to select individual agents. One was the frequency of that agent's association with the MeSH (Medical Subject Headings in PubMed) 
term "Anesthesia" (Table 1). The name of a drug and the term "Anesthesia" were placed in the search box, and the number of PubMed articles on that combination of terms during 2013-2017 was determined. An agent was included if the number of PubMed articles on it (in combination with the term "Anesthesia") was $=/>50$. Another inclusion criterion was the degree of commonness of the association. This was calculated by comparing the number of PubMed articles containing the drug's name in combination with the term "Anesthesia" relative to articles with the drug's name without "Anesthesia" (percent of total, Table 1). An agent was included if the percentage was $=/>5.0$. As a result, the following 25 names were included: alfentanil, bupivacaine, desflurane, dexmedetomidine, diazepam, etomidate, fentanyl, hydromorphone, isoflurane, ketamine, lidocaine, meperidine, mepivacaine, midazolam, morphine, oxycodone, prilocaine, propofol, remifentanil, ropivacaine, sevoflurane, sufentanil, tetracaine, thiopental, and tramadol.

\section{Results}

Table 2 presents the number of Google Web pages during the first and the last (7th) study periods. During the first period only half of the drugs had more than 10 Web pages. But by the last period, the number of pages had increased dramatically, to the degree that several drugs had more than 10,000 pages. In contrast to the increases in the number of Google pages, increases in the number of PubMed articles were much smaller.

Table 3 presents the time courses of growth in the number of Google Web pages for three agents exemplifying three categories of drugs: general anesthetics (isoflurane), local anesthetics (lidocaine), and opioids (fentanyl). With all of these drugs, there were substantial increases in the number of Google pages during every 5-year period, with only one exception: isoflurane, 2008-2012. With lidocaine and fentanyl the number of pages increased by more than $100 \%$ in many 5 -year periods. As a result, by the 2013-2017 period the number of Google Web pages reached 9,680 for lidocaine and 15,800 for fentanyl. In contrast, increases in the number of PubMed articles were much smaller.

The rapidly growing dominance of the number of Google Web pages over the number of PubMed articles is presented in Figs. 1-3. The G/P Ratio, indicating the degree of dominance of general Google-reflected information over academic PubMed-reflected information, steadily increased for every agent. Before the 1993-1997 period, the number of Google Web pages on anesthetics represented only a fraction of the number of PubMed articles. By the 2013-2017 period, the relationship was completely reversed: the number of Google Web pages on any anesthetic was at least three times greater than the number of PubMed articles on the same drug. The degree of these increases demonstrated extreme variability among the studied agents, especially during the last period. In 2013-2017, the G/P Ratio for the 25 drugs varied from 3.0 (remifentanil) to 23.2 (oxycodone).

\section{Discussion}


The time course of the number of Google pages on drugs used for anesthesia demonstrated a very rapid growth in Web-reflected information. This is especially evident if the growth of the number of PubMed articles is used as a contrast. The ratio of Google Web pages to PubMed articles (Figs. 1-3) showed the steadily increasing dominance of the Web. Before the 1993-1997 period, the number of Google Web pages on anesthetics represented only a fraction of the number of PubMed articles (the Web was born in 1989; however, Google collected pertinent information for a number of preceding years). Nevertheless, by the 2013-2017period, the relationship was completely reversed: the number of Google Web pages on any anesthetic was at least three times greater than the number of PubMed articles. Although profound dominance of the number of Google Web pages over the number of PubMed articles is common to all studied agents, the degree of this dominance, reflected by the G/P Ratio, is very variable. However, this variability shows a clear trend: agents with a low G/P Ratio tend to be more associated with anesthesia compared to agents with high G/P Ratio. Thus, general anesthetics (sevoflurane, isoflurane, desflurane, propofol, and etomidate), local anesthetics (bupivacaine, ropivacaine, and mepivacaine), and certain opioids (remifentanil and sufentanil), that had a relatively low G/P Ratio (from 3.0 to 5.0) showed a high degree of association with the MeSH term "Anesthesia" ( from 50-85\%, Table 1). Conversely, agents with G/P Ratios above 18.0 (diazepam and oxycodone) showed an extremely low association with the term "Anesthesia" - below $10 \%$.

In order to use the changes in academic PubMed-reflected information as a contrast to the changes in general Google-reflected information, the requirements for drug searches in the two databases were made more equitable by counting only those PubMed articles and Google pages that had the name of a drug in the title ("term-in-title"). This profoundly reduced the number of both Web pages and PubMed articles compared to when the name of a drug is anywhere in the page (or article). In addition, such narrowing of the selection was much more dramatic with Google Search "term-in-title" Web pages than with PubMed "term-in-title" articles. The "term-in-title" approach has an important advantage, because it avoids the problem of differences between two systems of drug search in the text of the page (or article). PubMed has a well-developed system to search for drug's name in the text of an article that permits selection only when the information on a drug in the article is substantial. The Google search system does not provide such scrupulous selection. Therefore, the "term-in-title" approach is more equitable. The use of only nonproprietary drug names as well as the selection of results in English served the same purpose. Nevertheless, these steps to improve equitability did not obviate the role of the two most important factors in determining the differences in Google-reflected and PubMed-reflected information. First, PubMed, in contrast to Google, contains only academic and peer-reviewed information. Second, Google includes both non-academic and academic information reflecting a mixture of completely different sources. The three steps described above increase the equitability of the Google and PubMed systems and made their juxtaposition more revealing.

Thus, not unexpectedly, the growth of Google-reflected information on anesthetics exceeded the growth of PubMed-reflected information. This does not necessarily mean that research or clinical interest in anesthetics has decreased over the last few decades. However, the dominance of nonacademic information can have important consequences. One is the increased availability of both academic and 
non-academic information on the Web. Barriers between these two domains have become more permeable, especially for individuals who are not medical professionals. As a result, sources of information can easily become sources of confusion and disinformation, especially regarding the adverse effects of anesthetics. In general, it could be viewed as an Internet-fueled decline of barriers between professionals and lay people; this was presented even as alarming trend indicative of "dilution of expertise" - a phenomenon of our time by far not limited to medicine. ${ }^{7}$ There may be other repercussions of the constantly increasing dominance of Google-reflected information that are more difficult to assess and predict.

This is a starting point in addressing the history of growth in availability of general Google-reflected information on drugs used for anesthesia. The obvious limitations are associated with the narrow scope of searches: only Web pages with the name of a drug in the title of the page, only nonproprietary names of the drugs, and results only in English. Widening the scope of the drug searches might substantially alter the results.

In conclusion, general Google-reflected information is rapidly growing and, as a result, its dominance over academic PubMed-reflected information is constantly increasing.

\section{Abbreviations}

G/P Ratio = the ratio of Google Web pages to PubMed articles; PubMed $=$ a free search engine accessing primarily the Medline database of references on life sciences and biomedical topics; Term-in-title $=$ the name of a drug in the title of the Web page; Web = World Wide Web; Web page $=$ a document on the World Wide Web.

\section{Declarations}

Ethics approval - Not applicable.

Consent for publications - Not applicable.

Availability of data - All data generated or analyzed during this study are available from the corresponding author on reasonable request.

Funding - No funding for this study.

Author contributions - KV and IK have made contributions to conception, design, acquisition of data, analysis and drafting of manuscript

\section{Acknowledgements}

The authors thank Dr. Darin J. Correll for his help with the design of figures and editorial suggestions. 


\section{References}

1. Vlassakov KV. Kissin I. Changes in publication-based academic interest in local anesthetics over the past 50 years. J Anesth Hist. 2016;2:73-78.

2. Correll DJ, Vlassakov KV, Kissin I. Recent history of publication-based academic interest in general anesthetics. J Anesth Hist. 2018;4:109-114.

3. Vlassakov KV, Kissin I. Scientometrics of anesthetic drugs and their techniques of administration, 1984-2014. Drugs Des Devel Ther. 2014;8:2463-2473

4. Thelwall M, Vaughan L, Bjorneborn L. Webometrics. Annu Rev Inform Sci. 2005;39:81-135.

5. Larson MD. History of anesthetic practice. In: Miller RD, et al, eds. Miller's Anesthesia. 7th ed. Elsevier Saunders; 2010:3-24.

6. Brown DL, Fink BR. History of regional anesthesia. In: Cousins MJ, et al, eds. Cousins and Bridenbaugh's Neural Blockade. 4th ed. Wolters Kluwer; 2009:1-23.

7. Nichols T. The Death of Expertise: The Campaign Against Established Knowledge and Why It Matters. Oxford University Press, 1st ed. 2017.

\section{Tables}

Table 1. Frequency of study drugs association with term "1 "Anesthesia" 
Drug's Name ${ }^{2}$

Class

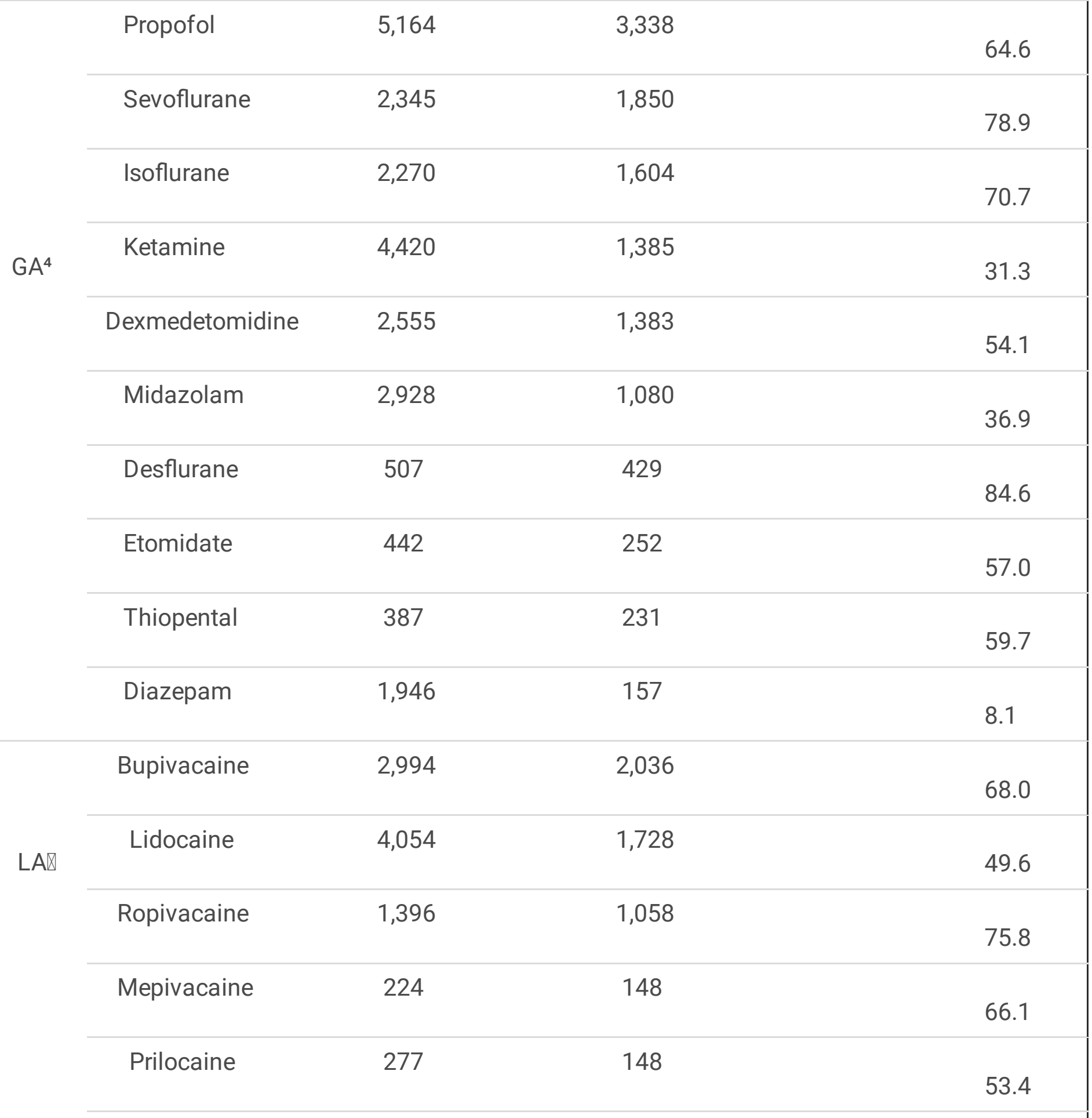




\begin{tabular}{|c|c|c|c|c|}
\hline & Cocaine & 7,401 & 60 & 0.8 \\
\hline \multirow{9}{*}{ Opioids } & Fentanyl & 3,957 & 1,941 & 49.0 \\
\hline & Morphine & 7,329 & 1,389 & 19.0 \\
\hline & Remifentanil & 1,583 & 1,215 & 76.0 \\
\hline & Tramadol & 1,644 & 375 & 22.8 \\
\hline & Sufentanil & 454 & 292 & 64.1 \\
\hline & Meperidine & 329 & 135 & 41.0 \\
\hline & Oxycodone & 1,335 & 129 & 9.7 \\
\hline & Hydromorphone & 482 & 90 & 18.7 \\
\hline & Alfentanil & 132 & 58 & 43.9 \\
\hline
\end{tabular}

\section{Footnotes for Table 1}

${ }^{1} \mathrm{MeSH}$ (Medical Subject Heading) term, the controlled vocabulary for articles in the databases of the US National Library of Medicine.

${ }^{2}$ Drugs with the number of articles associated with term "Anesthesia" $<50$ were not included in this study.

${ }^{3}$ All types of articles.

${ }^{4}$ General anesthetics and other drugs used for general anesthesia.

Q Local anesthetics

Table 2. Number of Google Web pages vs. number of PubMed articles 
Name

Drug's

Category

$\mathrm{GA}^{3}$

Dexmedetomidine

1983-1987

2013-2017

"term-

\begin{tabular}{|c|c|c|c|c|c|}
\hline \multirow{10}{*}{$\mathrm{GA}^{3}$} & Propofol & 78 & 8,450 & 182 & 2,349 \\
\hline & Sevoflurane & $x$ & 3,930 & 29 & 1,195 \\
\hline & Isoflurane & 97 & 2,880 & 468 & 789 \\
\hline & Ketamine & 164 & 17,900 & 490 & 2,309 \\
\hline & Dexmedetomidine & $x$ & 9,640 & $x$ & 1,978 \\
\hline & Midazolam & 10 & 4,360 & 409 & 850 \\
\hline & Desflurane & $x$ & 927 & $x$ & 244 \\
\hline & Etomidate & 78 & 986 & 238 & 214 \\
\hline & Thiopental & $x$ & 460 & 196 & 84 \\
\hline & Diazepam & 420 & 5,570 & 1,165 & 302 \\
\hline \multirow{6}{*}{$\mathrm{LA}^{4}$} & Bupivacaine & 125 & 4,800 & 435 & 1,018 \\
\hline & Lidocaine & 211 & 9,680 & 703 & 1,320 \\
\hline & Ropivacaine & $x$ & 2,090 & $x$ & 524 \\
\hline & Mepivacaine & $x$ & 274 & 34 & 60 \\
\hline & Prilocaine & $x$ & 454 & 48 & 80 \\
\hline & Tetracaine & $x$ & 450 & 65 & 73 \\
\hline \multirow{6}{*}{ Opioids } & Fentanyl & 230 & 15,800 & 545 & 1,199 \\
\hline & Morphine & 749 & 16,100 & 2,438 & 2,297 \\
\hline & Remifentanil & $x$ & 2,000 & $x$ & 705 \\
\hline & Tramadol & $x$ & 14,100 & 21 & 698 \\
\hline & Sufentanil & $x$ & 847 & 86 & 187 \\
\hline & Meperidine & 10 & 651 & 114 & 66 \\
\hline
\end{tabular}

Number of PubMed "termin-title" articles ${ }^{2}$ 


\begin{tabular}{|lcccc|} 
Oxycodone & $x$ & 10,900 & 10 & 470 \\
\hline Hydromorphone & $x$ & 1,200 & 19 & 122 \\
\hline Alfentanil & 50 & 233 & 181 & 52 \\
\hline
\end{tabular}

${ }^{1}$ Web pages with a term representing the name of an agent appearing in the title of the page (Google's Advanced Search).

${ }^{2}$ PubMed articles with a term representing the name of an agent in the article's title.

${ }^{3}$ General anesthetics and other drugs used for general anesthesia.

${ }^{4}$ Local anesthetics.

$x-$ No results $<10$.

Table 3. Time courses of growth in number of Google Web pages and PubMed articles on isoflurane, lidocaine, and fentanyl 


\begin{tabular}{|c|c|c|c|c|c|}
\hline \multirow[b]{3}{*}{ Drug's Name } & \multirow[t]{3}{*}{ Years } & \multicolumn{2}{|c|}{$\begin{array}{l}\text { Google } \\
\text { "term-in-title" } \\
\text { Web pages }\end{array}$} & \multicolumn{2}{|c|}{$\begin{array}{l}\text { PubMed } \\
\text { "term-in-title" } \\
\text { articles }\end{array}$} \\
\hline & & Number $^{1}$ & $\begin{array}{l}\text { Degree } \\
\text { of }\end{array}$ & Number ${ }^{3}$ & $\begin{array}{l}\text { Degree } \\
\text { of }\end{array}$ \\
\hline & & & Change $^{2}$ & & Change $^{2}$ \\
\hline \multirow{7}{*}{ Isoflurane } & $83-87$ & 97 & $x$ & 468 & $x$ \\
\hline & $88-92$ & 217 & +++ & 749 & + \\
\hline & $93-97$ & 387 & + & 888 & + \\
\hline & $98-02$ & 771 & + & 739 & - \\
\hline & 03-07 & 1,380 & + & 701 & - \\
\hline & 08-12 & 1,170 & - & 677 & + \\
\hline & $13-17$ & 2,880 & +++ & 789 & + \\
\hline \multirow{7}{*}{ Lidocaine } & $83-87$ & 211 & $x$ & 703 & $x$ \\
\hline & 88-92 & 281 & + & 821 & + \\
\hline & $93-97$ & 585 & +++ & 850 & + \\
\hline & $98-02$ & 1,570 & +++ & 971 & + \\
\hline & 03-07 & 2,370 & ++ & 989 & + \\
\hline & 08-12 & 3,200 & + & 1,198 & + \\
\hline & $13-17$ & 9,680 & +++ & 1,320 & + \\
\hline \multirow{7}{*}{ Fentanyl } & 83-87 & 230 & $x$ & 545 & $x$ \\
\hline & $88-92$ & 346 & ++ & 792 & + \\
\hline & $93-97$ & 450 & + & 705 & - \\
\hline & $98-02$ & 1,070 & +++ & 749 & + \\
\hline & 03-07 & 2,210 & +++ & 826 & + \\
\hline & $08-12$ & 2,690 & + & 955 & + \\
\hline & $13-17$ & 15,500 & +++ & 1,199 & + \\
\hline
\end{tabular}

${ }^{1}$ Number of Web pages with the name of a drug in the title of the page. 
${ }^{2}$ Degree of change in the number of Web pages during a 5-year period compared with the previous period: +++ increase $=/>100 \%,++$ increase $=/>50 \%,+$ any increase, - any decrease.

${ }^{3}$ Number of articles with the name of a drug in the title of the article.

$x-$ No results.

Figures

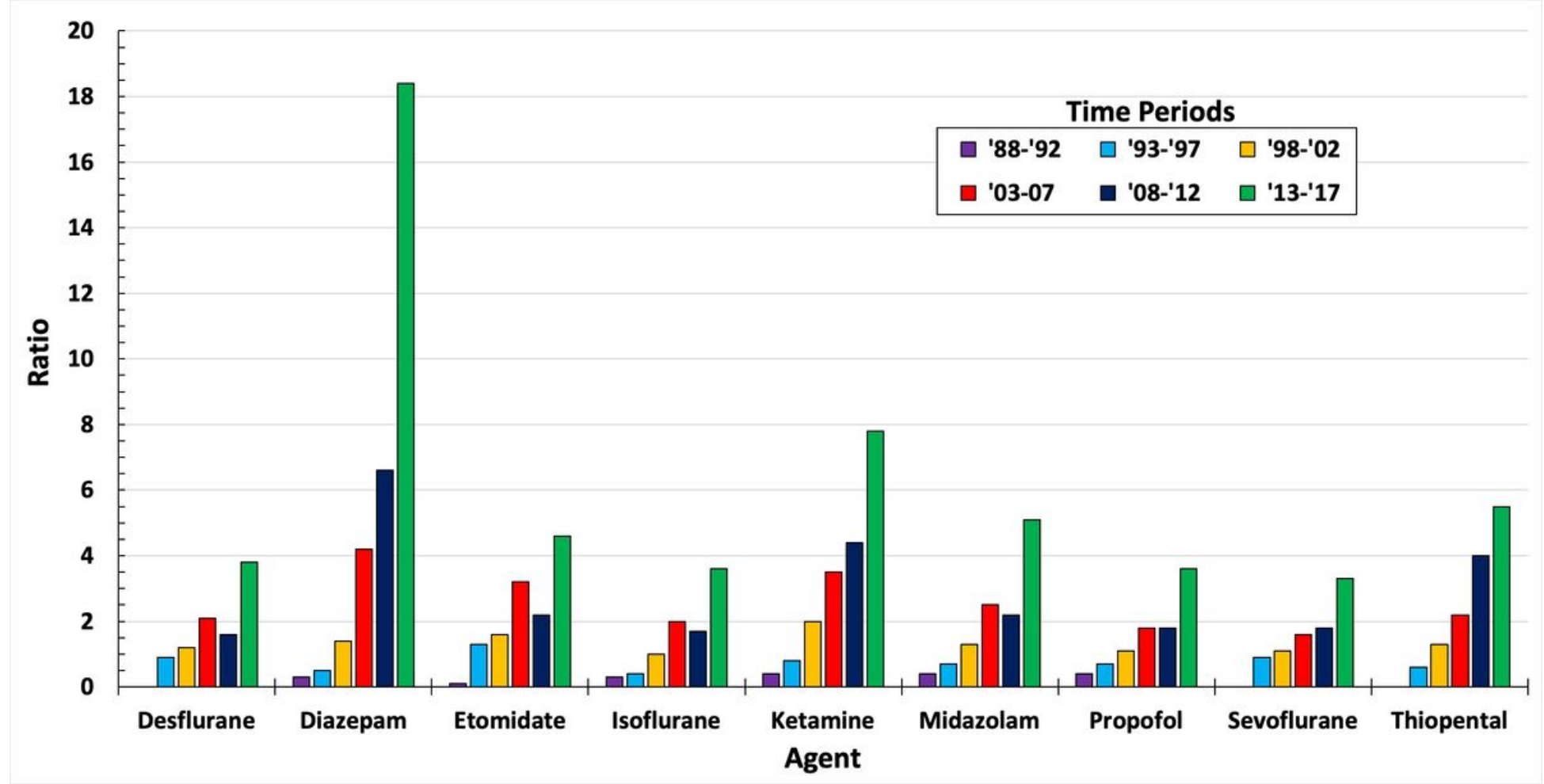

Figure 1

Relationship1 between Google Web pages and PubMed articles with drugs used for general anesthesia. 1 Ratio: number of Google "term-in-title" 2 Web pages to the number of PubMed "term-in-title" articles in decimals (G/P Ratio). 2 "Term-in-title": term representing the name of an agent appearing in the title of the article or Web page. 


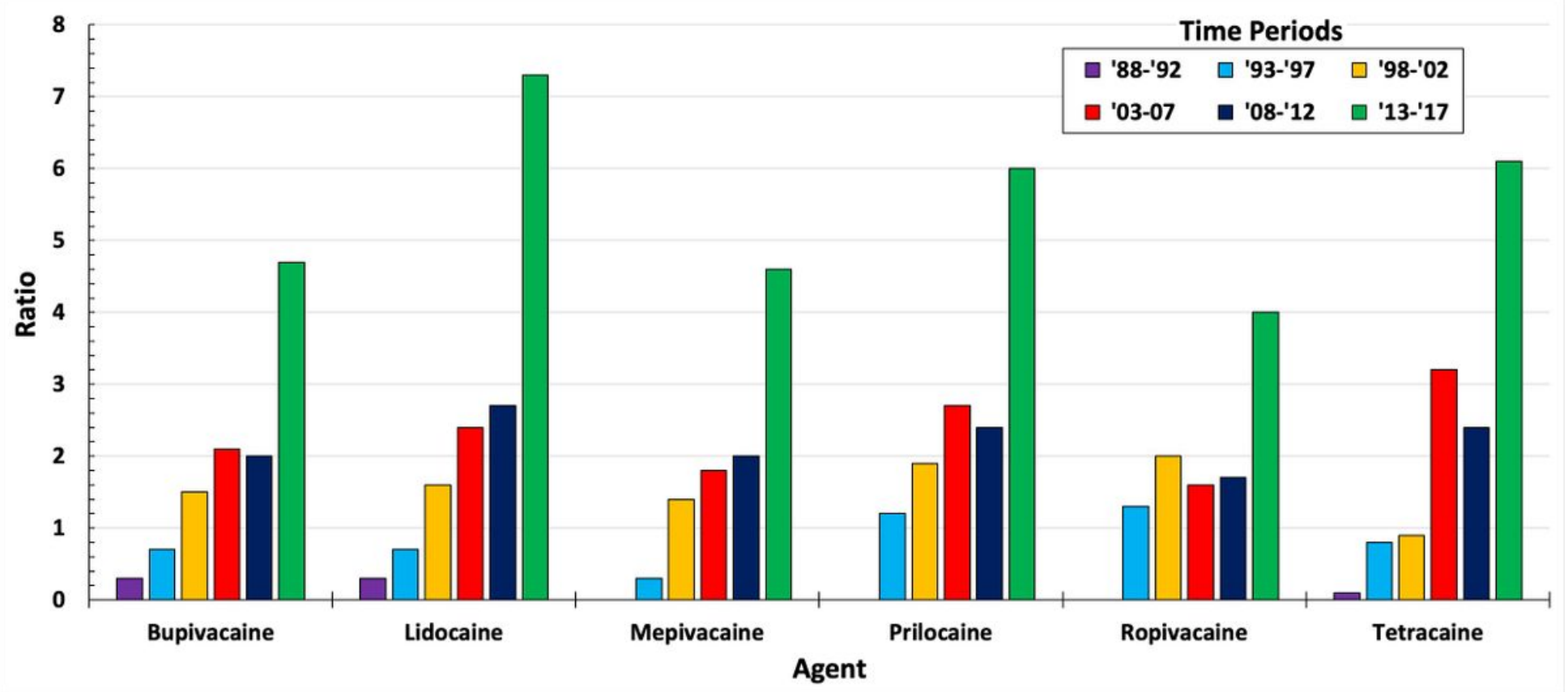

Figure 2

Relationship between Google Web pages and PubMed articles for local anesthetics.

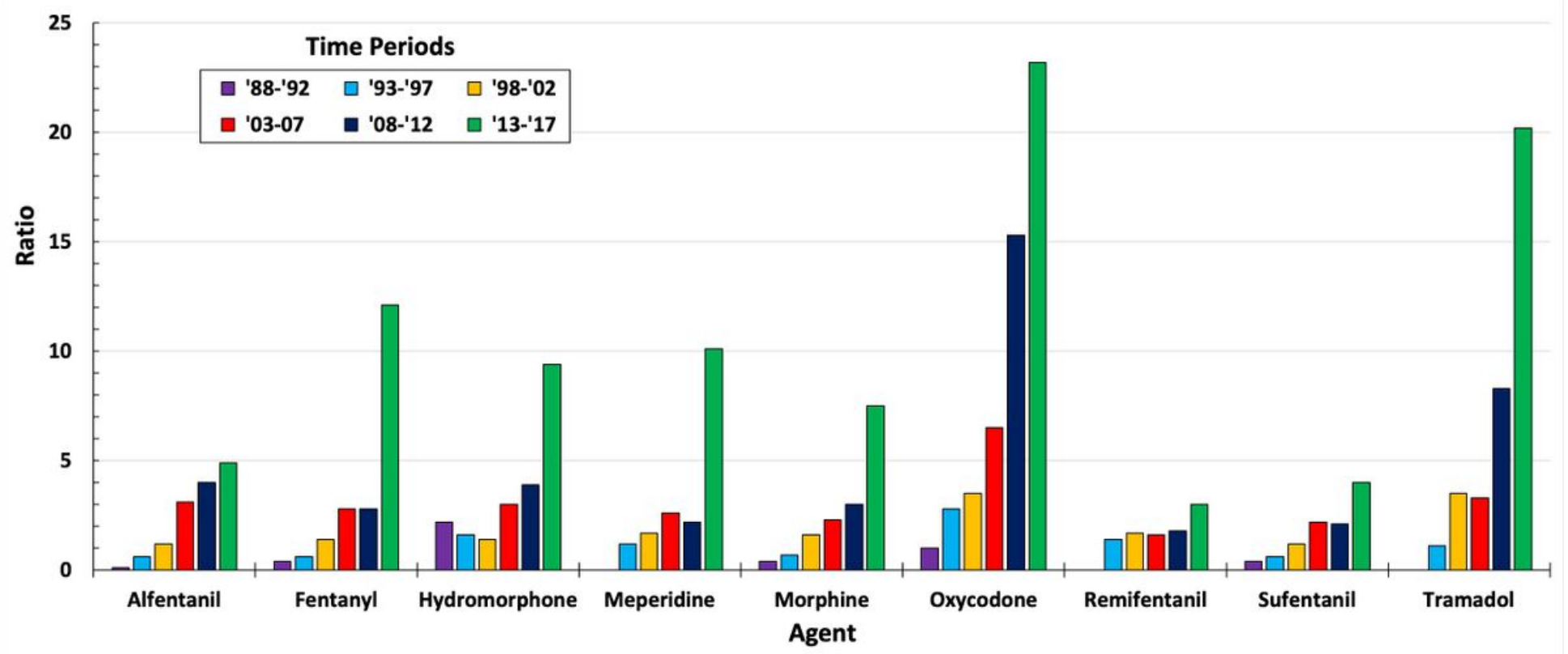

Figure 3

Relationship between Google Web pages and PubMed articles for opioids. 